\title{
VARIATIONS OF IONOSPHERIC PARAMETERS OVER ALMATY (KAZAKHSTAN) IN 1999-2013
}

\author{
S.N. Mukasheva \\ Institute of Ionosphere National Centre for Space Research \\ and Technology, \\ Almaty, Kazakhstan, snmukasheva@gmail.com

\section{V.I. Kapytin} \\ Institute of Ionosphere National Centre for Space Research \\ and Technology, \\ Almaty, Kazakhstan, kapytinsanct@mail.ru
}

\author{
A.M. Malimbayev \\ Institute of Ionosphere National Centre for Space Research \\ and Technology, \\ Almaty,Kazakhstan,nanozavr@mail.ru
}

\begin{abstract}
The paper presents the results of a study of the behavior of ionospheric parameters of the total electron content, $I(t)$, and electron density in the maximum F2 layer, $N_{\mathrm{m}}$, over Almaty (Kazakhstan) [43.25 $\mathrm{N} ; 76.92^{\circ} \mathrm{E}$ ] in 1999-2013. The time interval under study covers different solar activity levels. We have shown that at $F 10.7>175$ in summer and at $F 10.7>225$ in winter there is a saturation effect, i.e. with increasing solar activity level values of $I(t)$ do not increase. The observed nonlinear relationship between the total electron content of the ionosphere and the solar radiation flux F10.7 results from the nonlinear relationship between the solar ultraviolet radiation and the solar radiation flux.
\end{abstract}

The study of the variability of the mid-latitude ionosphere parameters during different solar and geomagnetic activity levels has shown that the standard deviation $\sigma(x)$ and average shift $x_{\text {ave }}$ of $I(t)$ and $N_{\mathrm{m}}$ fluctuations relative to the quiet level weakly depend on solar activity, but greatly depend on geomagnetic activity when $F 10.7<100$.

Keywords: total electron content, solar activity, ionosphere.

\section{INTRODUCTION}

Radio sounding of the ionosphere by global positioning system signals enables continuous monitoring of Earth's ionosphere [Afraimovich, Perevalova, 2006]. Global Ionospheric Maps (GIM), designed at several research centers (JPLG, US; CODE, Switzerland, etc.), are a powerful modern tool for monitoring and studying the global and local ionospheric structures [Mannucci et al., 1998; Schaer et al., 1998a, b]. These studies are essential for understanding dynamic processes in near-Earth space. They make it possible to understand how external factors, such as solar activity, affect Earth's dynamic structure, in particular near-Earth space. In recent years, the variability of ionospheric parameters depending on solar and geomagnetic activity has been extensively studied [Araujo-Pradere et al., 2005; Mandrikova et al., 2018; Shreedevi et al., 2018; Bolaji et al., 2019]. Spatial variability of the ionosphere depending on season is examined using modern statistical methods, e.g. wavelet analysis [Shi et al., 2014]. Works are underway on modification of solar activity indices in the International Reference Ionosphere (IRI) and IRI extended to the plasmasphere (IRI-Plas) [Gulyaeva, 2016]. To examine the ionospheric electron density variability, a local empirical model of electron density for conditions of low geomagnetic activity, which can be applied to any solar activity level, is proposed [Deminov et al., 2015].

The authors have examined the variability of ionospheric parameters - total electron content $I(t)$ (TEC) and electron density in the maximum F2 layer $N_{\mathrm{m}}$ over Kazakhstan for a sufficiently long period covering different solar activity levels. Solar activity is characterized by the $F 10.7$ index — solar radiation flux at a wavelength of $10.7 \mathrm{~cm}$. Geomagnetic activity is characterized using the $A_{\mathrm{p}}$ index. The purpose of this work is to identify the relationship between ionospheric parameters and variations of external factors such as solar radiation flux. We report the results of the analysis of variability of ionospheric parameters over Almaty (Kazakhstan) for two local times (midday and midnight), three seasons, low $(F 10.7<100)$ and high $(F 10.7>170)$ solar activity, undisturbed $\left(A_{\mathrm{p}}<9\right)$ and disturbed $\left(A_{\mathrm{p}}>27\right)$ geomagnetic conditions. The results obtained using modern satellite technologies, designed to work with GPS data on TEC, and also from measurements made at the Almaty vertical sounding station allow us to identify regional features of the mid-latitude ionosphere.

\section{DATA}

We have obtained TEC values $I(t)$ from IONEX maps in the GIM node $\left[42.5^{\circ} \mathrm{N} ; 75.0^{\circ} \mathrm{E}\right]$, closest to the coordinates of Almaty $\left[43.25^{\circ} \mathrm{N} ; 76.92^{\circ} \mathrm{E}\right]$. We have used GIM [ftp://cddis.gsfc. nasa.gov/pub/gps/products/ ionex] in IONEX format, calculated by the Center for Orbit Determination (CODE) in Europe, University of Berne, Switzerland from data gathered by more than 150 GPS receiving stations. Each IONEX-dat file contains vertical TEC values per day on the universal time scale (UT) with a temporal resolution of $2 \mathrm{hrs}$. Vertical TEC is calculated with respect to solar-geomagnetic conditions from spherical harmonic formulas [Afraimovich, Perevalova, 2006]. The universally accepted TEC unit is TECU (total electron content unit), equal to $10^{16} \mathrm{~m}^{-3}$. The behavior of TEC is examined together with $N_{\mathrm{m}}$ variations, measured at the Almaty vertical sounding station $\left[43.25^{\circ} \mathrm{N} ; 76.92^{\circ} \mathrm{E}\right]$. 


\section{RESULTS AND DISCUSSION}

\section{Ionospheric parameters versus solar activity} level

Consider variations of ionospheric parameters over the period 1999-2013, which covers different solar activity levels: high (1999-2002) when the solar radiation

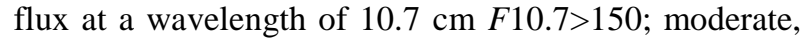
$F 10.7=100 \div 150(2003-2004$ - the descending phase of solar activity and 2011-2013 — the ascending phase of solar activity and abnormally low solar maximum); low, $F 10.7<100$ (2005-2010 with the deepest solar minimum over the past 100 years). The development of solar cycle 24 and its features are described in [Ishkov, 2012; Bruevich et al., 2018].

Figure 1, $a$ shows variations of the daily $F 10.7$ index. Information has been obtained from the website of the Space Weather Prediction Center of National Oceanic and Atmospheric Administration (NOAA) [http://www.swpc.noaa.gov]. Variations of midday and midnight $I(t)$ for 1999-2013 are shown in Figure 1, $b$ and $c$ respectively. The solid thick curve indicates the running average with the 81-day time window, constructed to eliminate seasonal variations.

Annual averages of $F 10.7$, midday and midnight $I(t)$, and $N_{\mathrm{m}}$ are listed in Table 1 . Midday $I(t)$ decreases $\sim 5$ times - from 63.1 TECU in solar maximum (1999) to 12.7 TECU in solar minimum (2009).
Midday $N_{\mathrm{m}}$ decreases $\sim 4.3$ times - from $175.6 \cdot 10^{10}$ $\mathrm{m}^{-3}$ in solar maximum (2001) to $40.3 \cdot 10^{10} \mathrm{~m}^{-3}$ in solar minimum (2008). Midnight $I(t)$ decreases $\sim 3$ times from 18.3 TECU in solar maximum (2002) to 6.1 TECU in solar minimum (2008). Midnight $N_{\mathrm{m}}$ decreases 2.6 times - from $41.7 \cdot 10^{10} \mathrm{~m}^{-3}$ in solar maximum (2000) to $16.1 \cdot 10^{10} \mathrm{~m}^{-3}$ in solar minimum (2008 and 2009).

The midnight values of both TEC and electron density at the maximum F2 layer during the years of solar maximum reach their midday values during the years of solar minimum: $(15 \pm 3)$ TECU and $(41 \pm 3) \cdot 10^{10} \mathrm{~m}^{-3}$ respectively.

Regression dependences of midday winter (upper panel) and summer (lower panel) $I(t)$ on solar activity level for 1999-2013 are shown in Figure 2. The regression dependences were obtained from 1201 midday winter values (November, December, January, February) and 1260 midday summer values (May, June, July, August) of $I(t)$ for 1999-2013. When $F 10.7>100$, the midday $I(t)$ in winter is higher than in summer, and this difference increases with increasing solar activity.

There is a positive correlation between midday winter $I(t)$ and solar activity at $F 10.7<225$. The regression dependence can be represented as a linear function $y=b_{1} x+b_{0}$, where $b_{1}=0.315, b_{0}=-12.172$, a regression coefficient $R_{\mathrm{sq}}=0.85$. When $F 10.7>225$ there is a saturation effect in winter, i.e. with increasing solar activity $I(t)$
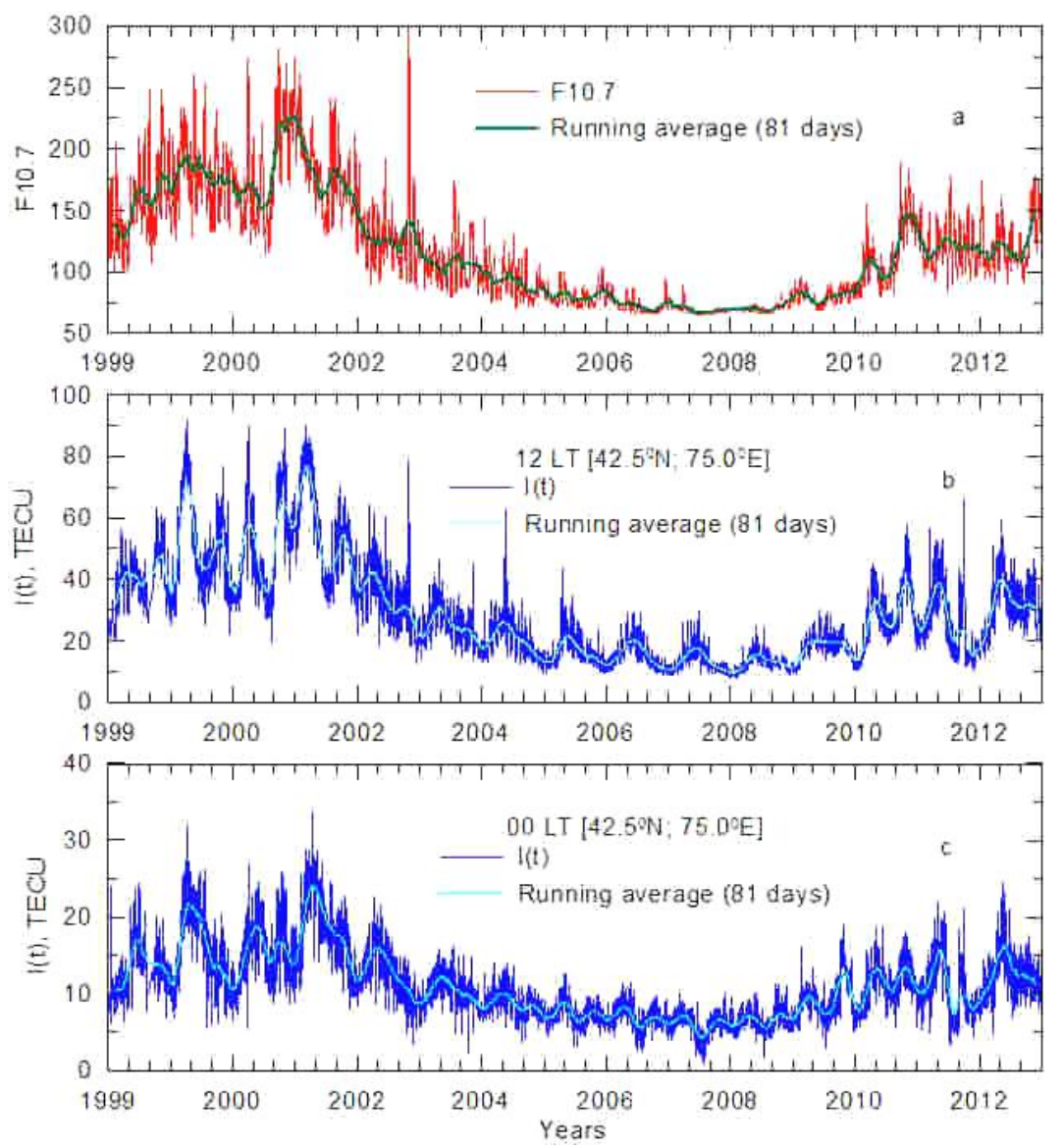

Figure 1. Variations in solar radiation flux at a wavelength of $10.7 \mathrm{~cm} F 10.7(a)$, midday $(b)$ and midnight $(c)$ TEC values $I(t)$, obtained from IONEX maps in the GIM node $\left[42.5^{\circ} \mathrm{N} ; 7^{\circ} \mathrm{E}\right]$, for $1999-2013$. The solid thick curve is the running average with the 81-day time window 
Annual average solar activity index $F 10.7$, midday and midnight

TEC $I(t)$ and electron density in the maximum F2 layer $N_{\mathrm{m}}$

\begin{tabular}{|c|c|c|c|c|c|c|}
\hline \multirow{3}{*}{ Years } & \multicolumn{5}{|c|}{ Annual averages } & \multirow{3}{*}{ Solar activity levels } \\
\hline & \multirow{2}{*}{$F 10.7$} & \multicolumn{2}{|c|}{$I(t)$, TECU } & \multicolumn{2}{|c|}{$N_{\mathrm{m}}, 10^{10} \mathrm{~m}^{-3}$} & \\
\hline & & $12 \mathrm{LT}$ & $00 \mathrm{LT}$ & $12 \mathrm{LT}$ & $00 \mathrm{LT}$ & \\
\hline 1999 & 153.7 & 63.1 & 13.2 & 131.5 & 31.0 & \multirow{4}{*}{$\begin{array}{l}\text { High } \\
F 10.7>150\end{array}$} \\
\hline 2000 & 179.5 & 50.6 & 15.9 & 147.3 & 41.7 & \\
\hline 2001 & 181.5 & 50.1 & 15.4 & 175.6 & 29.8 & \\
\hline 2002 & 179.5 & 56.3 & 18.3 & - & - & \\
\hline 2003 & 128.8 & 33.2 & 12.7 & 104.9 & 26.2 & \multirow{2}{*}{$\begin{array}{l}\text { Moderate (descending phase of solar activity) } \\
F 10.7=100 \div 150\end{array}$} \\
\hline 2004 & 106.5 & 24.4 & 10.3 & 83.4 & 26.2 & \\
\hline 2005 & 91.7 & 20.1 & 8.7 & 67.9 & 20.8 & \multirow{6}{*}{$\begin{array}{l}\text { Low (years with the deepest solar minimum } \\
\text { over the past } 100 \text { years) } \\
F 10.7<100\end{array}$} \\
\hline 2006 & 80.0 & 16.1 & 7.5 & 54.0 & 18.9 & \\
\hline 2007 & 73.1 & 15.2 & 6.9 & 47.7 & 17.0 & \\
\hline 2008 & 69.0 & 13.2 & 6.1 & 40.3 & 16.1 & \\
\hline 2009 & 70.6 & 12.7 & 6.5 & 41.7 & 16.1 & \\
\hline 2010 & 80.1 & 17.9 & 9.2 & 57.3 & 19.8 & \\
\hline 2011 & 113.4 & 27.9 & 11.3 & 83.4 & 25.1 & \multirow{3}{*}{$\begin{array}{l}\text { Moderate (ascending phase and abnormally } \\
\text { low solar maximum) } F 10.7=100 \div 150\end{array}$} \\
\hline 2012 & 119.9 & 25.3 & 10.6 & 98.2 & 27.4 & \\
\hline 2013 & 122.8 & 31.1 & 12.6 & 104.9 & 27.4 & \\
\hline
\end{tabular}
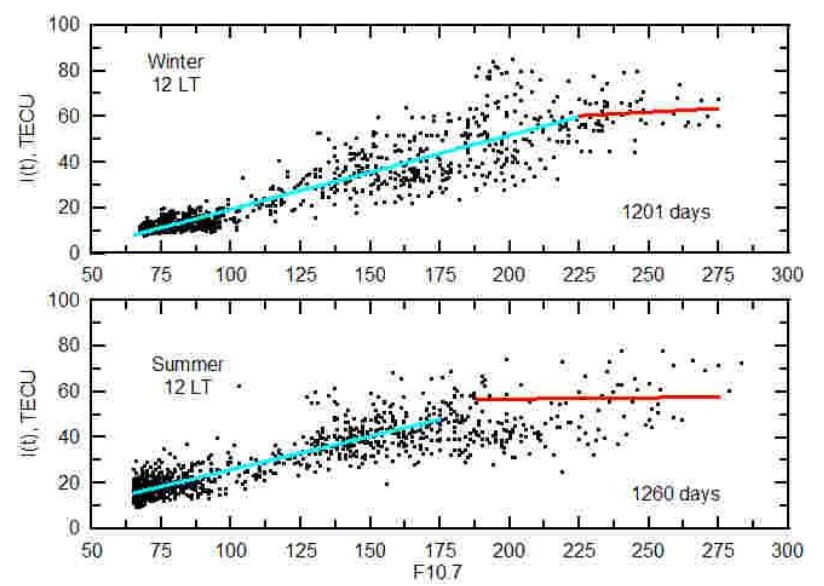

Figure 2. Regression dependence of midday winter (top) and summer (bottom) TEC values on solar activity level

no longer increases: $I(t)=(60 \pm 18)$ TECU. For summer conditions at $F 10.7<175$, the regression dependence can be represented as a linear function with $b_{1}=0.293, b_{0}=$ 3.477 with a regression coefficient $R_{\mathrm{sq}}=0.80$. The saturation effect occurs in summer when $F 10.7>175$ : $I(t)=(55 \pm 18)$ TECU. We have revealed the tendency for saturation of the ionosphere at high values of $F 10.7$ from data on the Faraday effect when receiving signals with a frequency $f=136.112 \mathrm{MHz}$ from the geostationary satellite ETS-II for the period from September 1985 to December 1989 at the radio test site Orbita (Almaty, $43.2^{\circ} \mathrm{N} ; 76.9^{\circ} \mathrm{E}$ ) [Mukasheva, 1999].

A similar dependence of TEC on the solar radiation flux is discussed in [Balan et al., 1993]; the authors report results of the TEC analysis based on data from five stations in the Northern Hemisphere for the period from December 1980 to December 1985 when the solar radiation flux varied from 66 to 303 units. Balan et al. [1993] note that the observed nonlinear relationship between TEC and F10.7 is the result of the nonlinear relationship between the solar ultraviolet radiation and the solar radiation flux at a wavelength of $\lambda=10.7 \mathrm{~cm}$, which is confirmed by model calculations and satellite measurements [Titheridge, 1973; Tobiska, 1991; Shreedevi et al., 2018]. So, according to [Balan et al., 1993], variations of the entire solar ultraviolet radiation range show a linearly increasing relationship with $F 10.7$ to $F$ $10.7<200$. When $F 10.7>200$, we can see the following:

1) the total solar ultraviolet flux $(50-1050 \AA)$ increases very slowly with $F 10.7$;

2) solar ultraviolet radiation fluxes, which play a significant role in heating the thermosphere, in chromospheric lines He II (303.78 $\AA$ ) and H Lyman- $\beta$ (1025.72 $\AA$ ) and 850-900 $\AA$ chromospheric emissions do not change with increasing $F 10.7$;

3) solar ultraviolet radiation fluxes in the coronal lines Fe XV (284.15 $\AA$ ) and 300-350 Å coronal emissions even decrease with increasing $F 10.7$;

4) solar ultraviolet radiation fluxes in the Lyman- $\alpha$

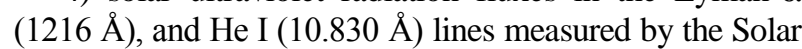
Mesosphere Explorer (SME) during solar cycle 21 also do not change with increasing $F 10.7$.

Bruevich et al. [2018] by examining the hysteresis effect (which manifests itself in an ambiguous relationship between solar radiation fluxes during ascending and descending phases of solar activity) also show that daily values of the flux in the Lyman- $\alpha$ line $(1216 \AA)$ when $F 10.7>\sim 180-200$ do not increase with F10.7.

\section{Variability of the mid-latitude ionosphere at different solar and geomagnetic activity levels}

The results of the analysis of variability of the ionospheric parameters $I(t)$ and $N_{\mathrm{m}}$ over Almaty (Kazakhstan) have been obtained for two local times (midday and midnight), three seasons (winter - November, December, January, February, equinox - March, April, September, October, summer — May, June, July, 
August), for low $(F 10.7<100)$ and high $(F 10.7>170)$ solar activity; undisturbed $\left(A_{\mathrm{p}}<9\right)$ and disturbed $\left(A_{\mathrm{p}}>27\right)$ geomagnetic conditions (see Tables 2 and 3). As a background level of $I(t)_{0}$ and $N_{\mathrm{m} 0}$, we have selected mean values at low geomagnetic activity $A_{\mathrm{p}}<9$ depending on solar activity level $(F 10.7<100$ and $F 10.7>170)$, time of day (LT=12 and LT=24), and season. The sample length $n$ for $I(t)_{0}$ if $F 10.7<100$ and $A_{\mathrm{p}}<9$ was 520 points for winter, 511 for equinox, 548 for summer; if $F 10.7>170$ and $A_{\mathrm{p}}<9$ it was 258 for winter, 177 for equinox, 287 for summer. The length of each sample depending on season and solar activity $n>450$. The selected averages were utilized to analyze properties of fluctuations of the ionospheric parameters from the standard deviation $\sigma(x)$ and average shift $x_{\text {ave }}$ [Deminov et al., 2015]:

$$
x_{\mathrm{ave}}=(1 / n) \Sigma_{i} x_{i} ; \sigma^{2}(x)=(1 / n) \Sigma_{i}\left(x_{i}-x_{\mathrm{ave}}\right)^{2} .
$$

Here, $x_{i}=\left(I(t)_{i} / I(t)_{0}-1\right) \cdot 100 \%$ or

$$
x_{i}=\left(N_{\mathrm{m}}(i)_{i} / N_{\mathrm{m} 0}-1\right) \cdot 100 \%,
$$

depending on the chosen ionospheric parameter. $\Sigma_{i}$ denotes summation over the index $i$ from 1 to $n$, where $n$ is the number of values of this sample.

The standard deviation $\sigma(x)$ of the ionospheric parameters considered, as seen from Table 2, weakly depends not only on solar activity, but also on season: on average $\sigma(x)$ varies between $27-30 \%$ in all the seasons

Table 2

Standard deviation $\sigma(x)$ and average shift $x_{\text {ave }}$ of $I(t)$ and $N_{\mathrm{m}}$ fluctuations relative to the quiet level above the station Almaty in the midday $(\mathrm{LT}=12)$ and midnight $(\mathrm{LT}=24)$ for three seasons (winter, equinox, summer) at low $(F 10.7<100)$ and high $(F 10.7>170)$ solar activity

\begin{tabular}{|l|l|l|l|l|l|l|l|l|}
\hline \multirow{2}{*}{ Season } & \multicolumn{9}{|c|}{ LT=12 } & \multicolumn{5}{c|}{ LT=00 } \\
\cline { 2 - 9 } & \multicolumn{9}{|c|}{$F 10.7<100$} & \multicolumn{2}{c|}{$F 10.7>170$} & \multicolumn{2}{c|}{$F 10.7<100$} & \multicolumn{2}{c|}{$F 10.7>170$} \\
\cline { 2 - 9 } & $\sigma(x), \%$ & $x_{\text {ave }}, \%$ & $\sigma(x), \%$ & $x_{\text {ave }}, \%$ & $\sigma(x), \%$ & $x_{\text {ave }}, \%$ & $\sigma(x), \%$ & $x_{\text {ave }}, \%$ \\
\hline$I(t)$ & 25.9 & 4.5 & 33.9 & 3.7 & 24.9 & 0.2 & 26.7 & 4.1 \\
\hline Winter & 29.4 & 4.2 & 24.5 & 0.8 & 25.7 & -0.7 & 30.4 & 0.1 \\
\hline Equinox & 27.8 & 3.7 & 22.4 & -0.4 & 32.7 & 4.8 & 23.5 & -1.0 \\
\hline Summer & 33.8 & 5.3 & 25.3 & 4.7 & 29.1 & 0.9 & 32.0 & 5.4 \\
\hline$N_{\mathrm{m}}$ & 31.9 & 3.3 & 23.3 & -3.1 & 29.4 & 1.0 & 36.1 & -2.3 \\
\hline Winter & 30.6 & 4.1 & 22.8 & -0.01 & 32.4 & 2.1 & 23.5 & -3.2 \\
\hline Equinox &
\end{tabular}

Table 3

Standard deviation $\sigma(x)$ and average shift $x_{\text {ave }}$ of $I(t)$ and $N_{\mathrm{m}}$ fluctuations relative to the quiet level above the station Almaty in the midday (LT=12) and midnight ( $\mathrm{LT}=24)$ for three seasons (winter, equinox, summer) under quiet $\left(A_{\mathrm{p}}<9\right)$ and disturbed $\left(A_{\mathrm{p}}>27\right)$

\begin{tabular}{|c|c|c|c|c|c|c|c|c|}
\hline \multirow{3}{*}{ Season } & \multicolumn{4}{|c|}{$\mathrm{LT}=12$} & \multicolumn{4}{|c|}{$\mathrm{LT}=00$} \\
\hline & \multicolumn{2}{|c|}{$A_{\mathrm{p}}<9$} & \multicolumn{2}{|c|}{$A_{\mathrm{p}}>27$} & \multicolumn{2}{|c|}{$A_{\mathrm{p}}<9$} & \multicolumn{2}{|c|}{$A_{\mathrm{p}}>27$} \\
\hline & $\sigma(x), \%$ & $x_{\text {ave }}, \%$ & $\sigma(x), \%$ & $x_{\text {ave }}, \%$ & $\sigma(x), \%$ & $x_{\text {ave }}, \%$ & $\sigma(x), \%$ & $x_{\mathrm{ave}}, \%$ \\
\hline \multicolumn{9}{|l|}{$I(t), F 10.7<100$} \\
\hline Winter & 21.7 & 0.034 & 46.4 & 60.0 & 25.4 & 0.015 & 24.6 & 12.8 \\
\hline Equinox & 27.0 & -0.001 & 42.5 & 38.3 & 26.5 & 0.027 & 23.6 & -4.6 \\
\hline Summer & 23.9 & 0.001 & 60.9 & 47.9 & 31.5 & 0.000 & 19.6 & 21.7 \\
\hline \multicolumn{9}{|l|}{$I(t), F 10.7>170$} \\
\hline Winter & 33.9 & 0.001 & 32.7 & 14.5 & 24.5 & 0.015 & 32.7 & 13.4 \\
\hline Equinox & 22.3 & 0.001 & 23.3 & 1.2 & 30.2 & 0.003 & 26.3 & -6.5 \\
\hline Summer & 21.1 & 0.001 & 28.9 & 3.0 & 22.3 & 0.002 & 28.9 & -4.5 \\
\hline \multicolumn{9}{|l|}{$N_{\mathrm{m}}, F 10.7<100$} \\
\hline Winter & 29.6 & 0.007 & 45.3 & 37.2 & 28.0 & 0.005 & 24.9 & -1.3 \\
\hline Equinox & 29.6 & 0.009 & 45.8 & 29.1 & 28.6 & 0.003 & 31.4 & 10.3 \\
\hline Summer & 26.7 & 0.011 & 56.4 & 46.0 & 31.6 & -0.006 & 35.0 & 23.8 \\
\hline \multicolumn{9}{|l|}{$N_{\mathrm{m}}, F 10.7>170$} \\
\hline Winter & 23.5 & 0.001 & 28.1 & 13.2 & 26.2 & -0.008 & 34.2 & 13.8 \\
\hline Equinox & 19.4 & 0.002 & 23.2 & -4.4 & 33.6 & -0.008 & 27.4 & -12.3 \\
\hline Summer & 21.1 & 0.004 & 26.3 & 0.0 & 21.7 & 0.005 & 24.5 & -9.2 \\
\hline
\end{tabular}
geomagnetic conditions depending on solar activity level

at any solar activity level. At any solar activity level and for both midday and midnight values of $I(t)$ and $N_{\mathrm{m}}$, the condition $\sigma^{2}(x)>>x_{\text {ave }}^{2}$ holds.

We can see (Table 3 ) that in all the seasons in the midday at $F 10.7<100$ and high geomagnetic activity $\left(A_{\mathrm{p}}>27\right)$ the standard deviation $\sigma(x)$ is greater $\sim 1.5-2.5$ times than that at low geomagnetic activity $\left(A_{\mathrm{p}}<9\right)$.
Since $I(t)_{0}$ and $N_{\mathrm{m} 0}$ were calculated for $A_{\mathrm{p}}<9$ depending on season and solar activity level, it is natural that $x_{\text {ave }}$ is close to zero when $A_{\mathrm{p}}<9$ (see Table 3 ). At $F 10.7<100$ and high geomagnetic activity, the condition $x_{\text {ave }}{ }^{2} \geq \sigma^{2}(x)$ holds, i.e. the average shift of $I(t)$ and $N_{\mathrm{m}}$ fluctuations relative to the quiet level exceeds the standard deviation of these fluctuations in absolute magnitude. When 
$F 10.7>170$, the variability depending on geomagnetic activity is less pronounced for both midday and midnight values of the standard deviation $\sigma(x)$ of $I(t)$ and $N_{\mathrm{m}}$. The variability of the ionosphere under quiet conditions is determined by internal atmospheric processes, electron density fluctuations at night determine diffuse ionospheric plasma flows between conjugate ionospheric regions, plasmaspheric fluxes, effects of magnetic substorms, thermospheric wind [Essex, Klobuchar, 1980; Shi et al., 2014; Deminov et al., 2011, 2015; Shreedevi et al., 2018].

\section{CONCLUSION}

Using modern GIM technologies and vertical sounding data from the Almaty station $\left[43.25^{\circ} \mathrm{N} ; 76.92^{\circ} \mathrm{E}\right]$, we have examined the behavior of ionospheric parameters $I(t)$ and $N_{\mathrm{m}}$ for the period from 1999 to 2013 over Kazakhstan. The period of interest covers different levels of solar activity. We have shown that the midday $I(t)$ in winter is higher than in summer if $F 10.7>100$, and this difference increases with increasing solar activity. There is a positive correlation between midday winter $I(t)$ and $F 10.7$ at $F 10.7<225$. The regression dependence can be expressed as a linear function with the regression coefficient $R_{\mathrm{sq}}=0.85$. When $F 10.7>175$ in summer and $F 10.7>225$ in winter there is a saturation effect, i.e. with increasing solar activity level $I(t)$ remains unchanged. The observed nonlinear relationship between the total electron content of the ionosphere and the solar radiation flux at a wavelength of $10.7 \mathrm{~cm}$ is the result of the nonlinear relationship between the solar ultraviolet radiation flux and the solar radiation flux, which is confirmed by model calculations and satellite measurements [Titheridge, 1973; Tobiska, 1991; Balan et al., 1993; Shreedevi et al., 2018].

The study of variability of the mid-latitude ionosphere parameters at different solar and geomagnetic activity levels has shown that the standard deviation $\sigma(x)$ and the average shift $x_{\text {ave }}$ of $I(t)$ and $N_{\mathrm{m}}$ fluctuations relative to the quiet level over the Almaty station $\left[43.25^{\circ} \mathrm{N} ; 76.9^{\circ} \mathrm{E}\right]$ weakly depend on solar activity level, and strongly depend on geomagnetic activity. At low solar activity $(F 10.7<100)$ and high geomagnetic activity, $x_{\text {ave }}$ is of the same order with $\sigma(x)$. At high solar activity $(F 10.7>170)$ the dependence on geomagnetic activity is less pronounced for midday and midnight values for both $\sigma(x)$ and $I(t)$ and $N_{\mathrm{m}}$.

There is no principal difference between $I(t)$ and $N_{\mathrm{m}}$ in terms of solar and geomagnetic activity level, TEC variability are largely determined by electron density variability in the maximum F2 layer. The latter allows us to use $I(t)$, derived from GIM, to monitor conditions of the mid-latitude ionosphere to solve problems of reliable operation of satellite navigation and mobile communication systems, which is important for Kazakhstan having an area of $2725000 \mathrm{~km}^{2}$ and the only vertical sounding station in Almaty.

The work was performed with budgetary funding of Special-Purpose Research and Development Program No. O.0799 of the Aerospace Committee of the Ministry of Digital Development, Innovation and Aerospace Industry of the Republic of Kazakhstan, Project No. 0118 RK00799.

\section{REFERENCES}

Afraimovich E.L., Perevalova N.P. GPS-monitoring verkhnei atmosfery Zemli [GPS-Monitoring of the Upper Atmosphere of the Earth]. Irkutsk, ISTP SB RAS, 2006, 480 p. (In Russian).

Araujo-Pradere E.A., Fuller-Rowell T.J., Codrescu M.V., Bilitza D. Characteristics of the ionospheric variability as a function of season, latitude, local time, and geomagnetic activity. Radio Sci. 2005, vol. 40, RS5009. DOI: 10.1029/ 2004RS003179.

Balan N., Bailey G.J., Jayachandran B. Ionospheric evidence for a nonlinear relationship between the solar e.u.v. and $10.7 \mathrm{~cm}$ fluxes during an intense solar cycle. Planet. Space Sci. 1993 , vol. 41 , no. 2 , pp. 141-145. DOI: $10.1016 / 0032-$ 0633(93)90043-2.

Bolaji O.S., Adebiyi S.J., Fashae J.B. Characterization of ionospheric irregularities at different longitudes during quiet and disturbed geomagnetic conditions. Atmos. Solar-Terr. Phys. 2019. vol. 182, pp. 93-100. DOI: 10.1016/j.jastp. 2018.11.007.

Bruevich E.A., Bruevich V.V., Yakunina G.V. Cyclic variations in the solar radiation fluxes at the beginning of the $21^{\text {st }}$ century. Moscow University Physics Bulletin. 2018, vol. 72, no. 2, pp. 216-222.

Deminov M.G., Deminova G.F., Zherebtsov G.A., Pirog O.M., Polekh N.M. Variability of parameters of the F2layer maximum in the quiet midlatitude ionosphere under low solar activity: 1. Statistical properties. Geomagnetism and Aeronomy. 2011, vol. 51, no. 3, pp. 348-355. DOI: 10.1134/ S0016793211020058.

Deminov M.G., Deminova G.F., Zherebtsov G.A., Polekh N.M. Properties of the F2-layer maximum density variability over Irkutsk under different levels of the solar and geomagnetic activity. Solar-Terrestrial Physics. 2015, vol. 1, no. 1, pp. 56-62. DOI: 10.12737/6558. (In Russian).

Essex E.A., Klobuchar J.A. Mid-latitude nighttime increases in the total electron content of the ionosphere. J. Geophys. Res. 1980, vol. 85, no. A11, pp. 6011-6020. DOI: 10.1029/ JA085iA11p06011.

Gulyaeva T.L. Modification of solar activity indices in the International Reference Ionosphere IRI and IRI-Plas models due to recent revision of sunspot number time series. SolarTerrestrial Physics. 2016, vol. 2, no. 3, pp. 87-98. DOI: $10.12737 / 22287$

Ishkov V.N. Tekushchii 24 tsikl solnechnoi aktivnosti: evolyutsiya, osobennosti, aktivnye yavleniya, prognoz razviti$y a$ [The current 24th cycle of solar activity: evolution, char: teristics, active phenomena, development forecast]. Po... 2012. http://www.izmiran.ru/POLAR2012/REPORTS/POLAR_ 2012_Ischkov.pdf (accessed 13 May 2019).

Mandrikova O., Polozov Y., Fetisova N., Zalyaev T. Analysis of the dynamics of ionospheric parameters during periods of increased solar activity and magnetic storms. $J$. Atmos. Solar-Terr. Phys. 2018, vol. 181, pp. 116-126. DOI: 10.1016/j.jastp.2018.10.019.

Mannucci A.J., Wilson B.D., Yuan D.N., Ho C.H., Lindqwister U.J., Runge T.F. A global mapping technique for GPS-derived ionosphere TEC measurements. Radio Sci. 1998, vol. 33, no. 3, pp. 565-582. DOI: 10.1029/97RS02707.

Mukasheva S.N. Morfologiya povedeniya integral'nogo elektronnogo soderzhaniya ionosfery nad Kazakhstanom (po dannym transionosfernogo zondirovaniya). Dis. ... kand. fiz.mat. nauk [Morphology of the behavior of the integrated elec- 
tron content of the ionosphere over Kazakhstan (according to TRANS-ionospheric sounding) Dr. phys. and math. sci. diss.] Almaty, 1999, 120 p. (In Russian).

Schaer S., Beutler G., Rothacher M. Mapping and predicting the ionosphere. Proc. of the IGS AC. Workshop. Darmstadt, Germany. February 9-11. 1998a, pp. 307-320.

Schaer S., Gurtner W., Feltens J. IONEX: The Ionosphere Map Exchange Format Version1. Proc. of the IGS AC. Workshop Darmstadt, Germany. February 9-11. 1998b, pp. 233-247.

Shi H., Zhang D., Liu Y., Hao Y. Analysis of the ionospheric variability based on wavelet decomposition. Sci. China Tech. Sci. 2014, vol. 58, iss. 1, pp. 174-180. DOI: 10.1007/ s11431-014-5709-8.

Shreedevi P.R., Choudhary R.K., Yadav S., Thampi S.V., Ajesh A. Variation of the TEC at a dip equatorial station, Trivandrum and a mid latitude station, Hanle during the descending phase of the solar cycle 24(2014-2016). J. Atmos. SolarTerr. Phys. 2018, vol. 179, pp. 425-434. DOI: 10.1016/j.jastp. 2018.09.010.
Titheridge J.E. The electron content of the southern midlatitude ionsphere, 1965-1971. J. Atmos. Solar-Terr. Phys. 1973, vol. 35, pp. 981-1001. DOI: 10.1016/0021-9169(73) 90077-9.

Tobiska W.K. Revised solar extreme ultraviolet flux model. J. Atmos. Solar-Terr. Phys. 1991, vol. 53, pp. 1005-1018. DOI: 10.1016/0021-9169(91)90046-A.

URL: http://www.swpc.noaa.gov (accessed May 20, 2019).

URL: ftp://cddis.gsfc.nasa.gov/pub/gps/products/ionex (accessed May 20, 2019).

How to cite this article

Mukasheva S.N., Kapytin V.I., Malimbayev A.M. Variations of ionospheric parameters over Almaty (Kazakhstan) in 1999-2013. Solar-Terrestrial Physics. 2019. Vol. 5. Iss. 4. P. 91-96. DOI: $10.12737 /$ stp-54201912. 